\title{
DA DECISÃO AO FATO - DECISÃO DECLARATÓRIA DE NULIDADE DE TESTAMENTO E MODULAÇÃO DE EFEITOS: UM ESTUDO DE CASO À PARTIR DOS JULGADOS RTJ 99 E RJTJRS 68
}

\author{
DICTUM TO FACT - DECLARATORY NULITY VERIDCT OF LAST \\ WILL TERM AND EFFECTS MODULATION: A CASE STUDY \\ PARTING FROM THE RULINGS RTJ 99 AND RJTJRS 68
}

\author{
David França Carvalho ${ }^{1}$ \\ Henrique Perlatto Moura ${ }^{2}$
}

\section{RESUMO}

A decisão judicial incorpora os fatos narrados pelos advogados e os transforma em direitos concretos. Ela, portanto, é a responsável pela conexão da abstração jurídica com a realidade fática. $\mathrm{O}$ que ocorre quando existe uma dissonância entre os efeitos jurídicos e os fatos experimentados? O que ocorreria com a realidade de um legatário, que exercera posse em razão de testamento com a ocorrência da Saisine, quando depara-se com uma sentença de nulidade de seu título, produzindo efeitos retroativos até a data da citação? Parte da doutrina e "jurisprudência" entendem que se altera produzindo efeitos de má fé a contar desse momento. A divergência instaurada se pauta na inconsistência na análise jurídica dos requisitos para que se perca a boa-fé. A análise será pautada pela ótica da teoria dos sistemas e considerando o direito como linguagem. A resposta que se chega é que a prolação da decisão parece ser o marco objetivo mais coerente com a lógica das disciplinas jurídicas postas. Para isso emprega-se como metodologia levantamento bibliográfico e pesquisa documental, bem como estudo de caso proposto à luz dos julgados apresentados pela doutrina como jurisprudência dominante.

\section{PALAVRAS-CHAVE:}

Decisão; teoria dos sistemas sociais; boa-fé; testamento; nulidade.

\begin{abstract}
The judicial decision absorbs the facts described by the lawyers and transforms that into concrete rights. It is, therefore, responsible for the connection of the juridical abstraction with the factual reality. What happens when there is an incompatibility between the juridical effects and the facts experienced? What would happen to the possession of a legatee, that exercised his right to possess holding a will in recurrence of the Saisine, when is confronted with a decision

\footnotetext{
${ }^{1}$ Advogado empresarial. Doutor em Direito Internacional e Comparado pela USP. Professor na Faculdade de Direito Milton Campos. Membro e Coordenador de Grupo na Academia Brasileira de Direito Internacional. Currículo lattes: http://lattes.cnpq.br/2643440740481449.

2 Advogado no escritório Ayres Ribeiro; Mestre em Direito pela Faculdade de Direito Milton Campos com Erasmus junto à Universidade de Lisboa; Especialista em Direito Tributário pelo instituto IED e IBET; Autor de artigos acadêmicos e professor universitário. Currículo lattes: http://lattes.cnpq.br/0721054953833990.
} 
that attests the nullity of this title, producing its effects retroactively until the subpoena? The doctrine and "jurisprudence" informs that it alters, producing the effects as exercised in bad faith after this moment. The arousing divergence is that there is an inconsistency between the legal analysis of the requirements needed for the legatee to lose the good faith status. The analysis will be founded under the scope of the system's theory, considering law as language. The answer given will be that the decision itself might be a better moment to consider, due to the logic of the legal system as a whole.

\section{KEYWORDS:}

Decision; system's; good faith; will; nullity.

\section{INTRODUÇÃO}

A decisão judicial é um dos atos mais importantes do ordenamento jurídico, uma vez que ilumina e estática estrutura normativa e dá resposta aos casos concretos. A interpretação permite que o julgador afira a validade das normas no sistema jurídico e atualize o sentido dos signos jurídicos. Isso é o que levou à compreensão do sistema jurídico como operacionalmente fechado e cognitivamente aberto: o direito se atualiza pelo meio simbólico generalizado da linguagem, partilhado por diversos subsistemas sociais e assim, atualizações culturais são incorporadas à interpretação jurídica.

A análise aqui tecida se embasa em uma sequência de atos jurídicos, convalidados pelo sistema, todos oriundos de um título viciado. A título exemplificativo, tem-se a hipótese do legatário possuidor, que herda uma propriedade rural por meio de testamento e passa a viver nela auferindo frutos. Não obstante ter havido pronunciamento judicial e a ocorrência da saisine, recebe uma citação informando que houve a instauração de um procedimento questionando a validade do testamento - título que lhe garantiu a propriedade - e, ao final de anos de discussão, a sentença declara a nulidade do instrumento. Poderia a sentença declaratória retroagir até a data da citação e tornar uma posse de boa-fé presumidamente de má fé e condenar o legatário à restituição dos frutos percebidos?

A construção do sistema jurídico, porém, para que sejam interpretadas as normas frente ao estímulo dos fatos, é dotada de extrema complexidade. Para explicar a lógica recursiva do 
direito, bem como a autopoiese e a coerência necessária nas comunicações oficiais do sistema - a decisão judicial - elenca-se como marco teórico os estudos de SCHWARTZ ${ }^{3}$ e LUHMANN $^{4}$ acerca da teoria dos sistemas sociais. com vista a entender as possíveis construções e caminhos que poderiam levar o julgador a construir uma visão crítica acerca da complexidade jurídica. O sistema se torna mais lógico quando respeita sua própria historicidade e, nesse sentido, assegura de forma mais eficaz a estabilidade das relações no contexto social. Enfatizando os preceitos constitucionais que iluminam a leitura da questão sob enfoque, visase demonstrar que a resposta "imediata", tal como apresentada pela doutrina a título de jurisprudência dominante, é somente uma simplificação que sequer parte de um caso semelhante. Tratar-se-ia de jurisprudência fantasma? É esse o caso dos julgados RTJ 99, de 1980, e RJTJRS 68, de 1977, citados por Gonçalves ${ }^{5}$.

Será respondida a pergunta acima por meio de revisão bibliográfica e pesquisa de julgados citados pela doutrina como paradigmas na temática. Ademais, será conduzido um estudo de caso para demonstrar os valores conflitantes entre planificação da complexidade por normas processuais frente às peculiaridades do caso concreto.

\section{DESENVOLVIMENTO}

\subsection{Considerações iniciais}

Um sistema é um conjunto de atos que se orienta por uma lógica intrínseca ao sistema que se materializa em uma classificação binária. A definição de sistema, para $\operatorname{LUHMANN}^{6}$, é obtida por meio da diferenciação do meio e do entorno. Dispondo sobre a abrangência e limitação dos sistemas, este informa que "El concepto de sistema significa, pues, algo que

\footnotetext{
${ }^{3}$ SCHWARTS, Germano. Introdução à teoria do sistema autopoiético do Direito. Ed. Porto Alegre: Livraria do advogado, 2005.

${ }^{4}$ LUHMANN, Niklas. Organización y decisión. Autopoiesis, acción y entendimiento comunicativo. $1^{\text {a }}$ Ed. Barcelona: Anthropos Editorial. 1997.; LUHMANN, Niklas. Sociedad y sistema: la ambición de la teoria. Ed. Barcelona: Ediciones Paidós Ibérica, 1984.; LUHMANN, Niklas. O Direito da Sociedade. São Paulo: Martins Fontes, 2016

5 GONÇALVES, Carlos Roberto. Direito Civil Brasileiro: Direito das Coisas. 10. Ed. V. 5. São Paulo: Saraiva. 2015.

${ }^{6}$ LUHMANN, Niklas. Sociedad y sistema: la ambición de la teoria. Ed. Barcelona: Ediciones Paidós Ibérica, 1984.
} 
realmente es un sistema, y por conseguinte assume la responsabilidad de la verificacíon de sus proposiciones en relación con la realidad" ". A realidade é absorvida pela organização sistêmica que, irritada pelo seu entorno, gera uma resposta (inputs/outputs). A dinâmica, derivada da teoria molecular de Maturama, explica as organizações sociais como estruturas orgânicas que se estruturam mediante comunicações que, dada a repetição e o surgir de padrões, orientam-se por uma mesma lógica, unindo-se em estruturas, formando sistemas.

No caso do direito, a lógica sistêmica gira entre Jurídico e não-Jurídico. A verificação deste enquadramento efetivo se dá por uma análise dos preceitos fundantes do sistema, neste caso a constituição, a legislação, bem como à perquirição de uma lógica construída pela jurisprudência, conjuntamente à interpretação dos fatos - traduzidos por meio de linguagem.

Essa classificação não serve somente para que as filosofias se percam em taxonomias complexas e abstrações infindáveis, mas sim para extrair novas perspectivas de problemas já conhecidos, delimitando novos paradigmas. Assim, outro aspecto de fundamental ponderação é a construção da lógica do sistema pela perspectiva de um terceiro observador. Esse terceiro tem acesso à toda dimensão dos atos praticados e, munido de outras informações, afere a juridicidade de tais fatos. O julgador assume esse papel e, sem acesso a todas as realidades, decide casos concretos e, assim, permite ao sistema que sejam solucionadas as provocações no sistema jurídico.

A jurisprudência, portanto, desenvolve, por meio de linguagem, as aplicações concretas dos preceitos abstratos já postos pelo legislador, sendo considerada criação de direito, mais especificamente, em sua unidade - a decisão judicial. Por meio de sua fundamentação lógica, bebendo nos fundamentos do próprio sistema, essa inova quando permite a abertura de sua linguagem para a aferição de novos contextos, provocando assim resultados diversos do padrão esperado. Essa inovação não pode ser feita ao alvedrio do julgador simplesmente por suas premissas pessoais, mas sim por meio de uma construção silogística e sistemática que extrai do caso concreto elementos a serem observados nas decisões futuras.

A da sentença judicial como produto da lógica jurídica, deve ter como referência a indefinição e polissemia da linguagem, mas seus efeitos podem ser prospectivos e retrospectivos - impactando situações já consolidadas pelo ordenamento.

\footnotetext{
${ }^{7}$ Id. p. 41.
} 
DONIZETTI $^{8}$, ao tratar da natureza das sentenças definitivas e seus efeitos, informa que, em sua classificação: "Podem ser: condenatórias, declaratórias e constitutivas"; avançando, o autor esclarece que as condenatórias, em razão da inovação no mundo jurídico, operam seus efeitos a contar de sua prolação, divergindo das declaratórias - que apenas constatam uma realidade jurídica. Não diverge a descrição de DONIZETTI ${ }^{9}$ de outros manuais de processualistas, tal como DIDIER ${ }^{10}$ - trata-se de uma simplificação de norma processual que modula o direito material sem se ater às complexidades do caso concreto.

Propomos que seja observada, sob o paradigma da teoria dos sistemas, o caso específico de decisão que reconhece a nulidade de um testamento. As formalidades legalmente impostas dão ao ato a aparência de rigidez procedimental, característica das disposições últimas de vontade, mantida apesar e em razão da morte. Este instrumento jurídico, considerando a sua rigorosa formalidade, apresenta variadas possibilidades para a ocorrência de nulidades - até mesmo sem que existam causadores dolosos. A implicação dessas ocorrências pode trazer consequências não desejadas pelo operador do direito que respalda uma interpretação constitucional harmônica, sob a luz de princípios e vetores interpretativos próprios.

A partir de então, tem-se que o ponto de partida do observador será a ocorrência de nulidade de um ato que já produziu seus efeitos tanto no mundo jurídico quanto no plano físico. Ato que transcorreu por meio de linguagem competente, qual seja, judicial ou extrajudicial. A concretude dessa linguagem, dessa maneira, gera efeitos no mundo jurídico, especificamente quando o código de validade do direito (jurídico e não jurídico) confirmar tal pertença. No caso em tela, um pedaço de papel garantidor da redistribuição dos bens em conformidade às vontades do de cujus, ainda que restrita à metade da totalidade do patrimônio, aos legatários. Estes, inclusive, munidos de posse e propriedade em decorrência e a partir da Saisine - princípio que dispõe acerca da imediata transmissão não só da propriedade, como também da posse.

Nota-se que um ato não jurídico, quando posto nessa cadeia, pode apresentar inconsistências de ordem prática: ocasionar a extinção de um ato por meio do reconhecimento

\footnotetext{
8 DONIZETTI, Elpídio. Classificação e efeitos das sentenças definitivas. Disponível em: http://genjuridico.com.br/2017/07/05/classificacao-e-efeitos-das-sentencas-definitivas/. Acesso em 29 de agosto de 2018.

${ }^{9}$ Id.

${ }^{10}$ DIDIER, Fredie; BRAGA, Paulo Sarna; OLIVEIRA, Alexandria de Oliveira. Curso de Direito Processual Civil. 10. Ed. V. 2. Salvador: Jus Podium. 2015.
} 
de nulidade acarretaria prejuízo para os terceiros de boa fé que, outrora, eram proprietários possuidores, e agora passam a meros detentores. A prolação de uma sentença declaratória levar, por disposição processual, à retrocessão dos efeitos até a data da citação contra terceiros de boafé deveria ser exceção no direito, uma vez que modifica a realidade que já se moldou em desfavor daquele que não tomou parte na formação do vício. A nulidade ocorre sob o entendimento de que o ato nunca integrou o ordenamento jurídico, não obstante ser o mesmo ato que criara a aparência de legalidade da posse testamentária pelo legatário.

Existe aqui uma aparente contradição, não enfrentada pela doutrina e jurisprudência predominantes, causada pela dissonância entre as decisões e atos prolatados e regidos sob a lógica jurídica, com uma consequente ruptura de expectativa. A perda do status de "jurídico" deveria ter o condão de alterar a classificação de uma posse já exercida e legitimada pelo próprio arranjo sistêmico, a partir de uma pressuposição ficta à posteriori? Pois é o que acontece, como aponta GONÇALVES ${ }^{11}$. Os efeitos de sua posse foram reais, mas a sua justificação perdeu o caráter de juridicidade com caráter retroativo. A consequência dessa ruptura, como veremos, é produzida em detrimento da pessoa que exerceu a posse, que tem sua classificação alterada, perdendo o status de boa-fé, mesmo enquanto amparada por justo título.

A construção é no sentido de apontar as inconsistências da resposta que seria a imediata, na tentativa de propor uma solução menos danosa para as partes envolvidas. Essa solução, conforme apontado, será obtida mediante a problematização das categorias de decisões, que moldam os efeitos dessas no mundo fenomênico. Contudo, a resposta dada pela doutrina de fixar como marco objetivo a citação, não atende às expectativas das decisões baseadas em decisões. É dizer, a melhor decisão é aquela que considera as predecessoras e projeta-se para o futuro, servindo de base para a realidade construída. Ignorar o passado é negar a realidade e a complexidade inerente advinda do ato de decidir.

A expulsão deste preceito normativo, anteposto à identificação do vício, atrai imediatamente para os legatários a obrigação de, além de devolver os bens que lhes foram legados, restituir os frutos ao espólio; como se todo o período que sucedeu à citação estivesse em uma zona comprometida, mas passível de modificação independentemente da aferição da conduta dos agentes envolvidos. A tratativa, dessa forma cerrada, se justificaria somente em

\footnotetext{
${ }^{11}$ GONÇALVES, Carlos Roberto. Direito Civil Brasileiro: Direito das Coisas. 10. Ed. V. 5. São Paulo: Saraiva. 2015 .
} 
um cenário no qual as partes envolveram-se com intenções de burlar, de forma culposa ou dolosa, a sistemática imposta pela declaração de vontade do de cujus. Ocorre que, em se tratando de decisão na qual participam mais vetores comunicativos, é imprescindível que seja investigada a relação dos sujeitos no sistema, devendo-se considerar tantas realidades quanto possível. CARVALHO ${ }^{12}$, tecendo considerações acerca da verdade para a teoria do direito, informa que

É pelo vínculo estabelecido entre uma proposição e as linguagens de determinado sistema que podemos aferir sua veracidade ou falsidade. Considera-se verdadeira a proposição condizente com o sentido comum, instituído dentro de um modelo. Destaca-se a importância da noção do sistema de referência para atribuição do valor verdade a qualquer informação ${ }^{13}$

Visa-se, portanto, a melhor resposta jurídica do sistema em relação a imanente realidade que, embora inexorável, é também construída pelo sistema.

Nesse sentido, o trabalho apresentará a forma que a decisão judicial se relaciona com a realidade, constituindo-se como ponte entre a abstração e a facticidade. Para isso, tentaremos compreender a autopoiese do direito, como descrita por SCHWARTS ${ }^{14}$, que auxiliará na construção do arcabouço dessa colisão que permite que o direito se feche tecnicamente, mas se atualize por meio da linguagem, retomando as diferenciações entre meio e entorno.

A posse, ora descrita, de um indivíduo que tem consigo um título garantidor de propriedade, será conceituada nos moldes do direito civil contemporâneo, com a apresentação dos conceitos colacionados nos manuais jurídicos. O importante é não restarem dúvidas acerca da classificação dos institutos apresentados, com o intuito de que a discussão se concentre na aplicação, nas implicações fáticas das abstrações jurídicas. Assim, a posse e suas classificações, no que tange à realidade fática do legatário, e, o testamento e a saisine, que o imbuem nesse papel, serão os preceitos conceituados e correlacionados com o caso discutido.

Uma importante consideração deve ser feita, uma vez que orientará parte das críticas tecidas pelo trabalho: a análise que será realizada da esfera judicial em relação à questão

\footnotetext{
${ }^{12}$ CARVALHO, Luiz Paulo Vieira. Direito das Sucessões. São Paulo: Atlas, 2014.

13 Id. p. 35.

${ }^{14}$ SCHWARTS, Germano. Introdução à teoria do sistema autopoiético do Direito. Ed. Porto Alegre: Livraria do advogado, 2005.
} 
apresentada, se pauta, principalmente, em dois julgados, citados por GONÇALVES ${ }^{15}$, que se demonstrarão incoerentes quando analisados no sentido apresentado pelo autor.

\subsection{Decisão e realidade: Um embate sob a ótica da burocratização}

As reflexões que serão tecidas no presente trabalho baseiam-se na estruturação da decisão judicial, como resultado da análise de diversos preceitos, alguns jurídicos e outros não. A análise simples do direito esvazia de sentido o próprio suporte físico inerente ao direito, qual seja, a linguagem.

SCHWARTZ ${ }^{16}$, ao tecer afirmações sobre a linguagem, demonstra a insuficiência da definição dos institutos em abstrato, sendo o direito sempre dependente dos contextos sobre o qual será aplicado.

as teses hermenêuticas da filosofia da linguagem ordinária, desde Wittgenstein, foram um avanço ao romperem com o apriorismo analítico do neopositivismo, acentuando o fato de que o sentido depende do contexto, da situação, do uso dos discursos $^{17}$

Nesse sentido, o direito se conforma mais à realidade do que a realidade se conforma ao direito, sem que a lógica jurídica seja violada. A linguagem permite a abertura da significação, enquanto o direito, propriamente dito, limita sua aplicação, em uma espécie de paradoxo aparente.

A autopoiese permite que o sistema seja "simultaneamente fechado e aberto, ou seja, é um sistema que tem repetição e diferença, tendo que equacionar no seu interior esse paradoxo, que os operadores do Direito vão usar como critério para tomar decisões" ${ }^{18}$ (p.38). Essa definição será importante para que o contexto, quando apresentado, seja integrado ao direito como um dos critérios para a tomada de decisão, afastando-se de uma aplicação apriorística dos institutos, que poderia trazer soluções que coloquem em risco o direito dos jurisdicionados.

\footnotetext{
${ }^{15}$ GONÇALVES, Carlos Roberto. Direito Civil Brasileiro: Direito das Coisas. 10. Ed. V. 5. São Paulo: Saraiva. 2015.

${ }^{16}$ SCHWARTS, Germano. Introdução à teoria do sistema autopoiético do Direito. Ed. Porto Alegre: Livraria do advogado, 2005.

17 Id. p. 22.

18 Id. p. 38.
} 
A decisão judicial deve ser vista como produto de um sistema que tem como elementos não só o ordenamento literal, mas também os pressupostos fáticos e o contexto social de uma sociedade. O judiciário não poderia, assim, como um poder subordinado ao legislativo, uma vez que utiliza da produção legislativa, criar direito do além. Quando efetivamente inova, o judiciário encontra amparo em produções já realizadas pelo sistema jurídico, em um arranjo de escolhas previamente feitas. A decisão, nesse sentido, é produto das decisões anteriores, projetando decisões futuras. A própria estrutura do sistema é tida pelo emaranhado de decisões, mas é limitada pela realidade. A realidade, por sua vez, é traduzida em linguagem e, assim, interpretada pelo judiciário, ressaltando a importância do contexto social dos agentes para a delimitação da realidade construída. Essa nova posição é possibilitada pela reinterpretação da função do julgador, que não mais é um exegeta, um aplicador mecânico de preceitos textuais. Os textos vão desempenhar um efeito em um contexto, em uma operação na qual o contexto se torna mais importante que o próprio texto, estritamente.

No entanto, o judiciário, tem a incumbência de julgar, independente da controvérsia apresentada - diferentemente do legislativo, que não é obrigado a legislar. Assim, SCHWARTZ", aponta que "Somente os tribunais são forçados a produzir as operações jurídicas em uma continuidade recursiva sem falhas" ${ }^{20}$. Essa obrigação se dá em razão da posição do judiciário no sistema jurídico, centro do encerramento operativo jurídico, uma vez que a resposta dada por esse poder encerra a discussão, ao menos no campo da controvérsia legal.

Após todo o trâmite de discussão judicial, com eventual interposição de recursos e decisões de tribunais superiores, existe a exaustão da esfera jurídica. Exatamente em razão dessa exaustão, dada impossibilidade de continuar a discussão com base em elementos que não "somente jurídicos", é que o direito acaba incorporando outros elementos de relevante teor para sua construção hígida. Melhor dizendo, não existem elementos somente jurídicos; razão pela qual a mera aplicação do direito não poderá, jamais, ser um fator que trará coerência para as decisões prolatadas, uma vez que os fatos apresentados. As irritações são percebidas pelo sistema pelo valor do sistema e de seus agentes, dando coerência ao direito e respondendo a problemas concretos da sociedade.

\footnotetext{
${ }^{19}$ Id.

${ }^{20}$ Id. p. 135.
} 
A realidade, nesse sentido, como afirma CARVALHO ${ }^{21}$, é composta apenas de linguagem, corroborando com as premissas de fechamento operacional e textura aberta. Com isso,

\begin{abstract}
A linguagem social só passa a ser linguagem jurídica quando o próprio sistema a seleciona e lhe confere tratamento jurídico por meio de suas estruturas (código e programa). Neste sentido, a programação assegura uma abertura cognitiva ao sistema em relação a seu ambiente, pois é ela que colhe as informações que são processadas no código lícito e ilícito, para dentro do sistema. ${ }^{22}$
\end{abstract}

Voltando ao caso: Um legatário, munido de um testamento, se imbui na posse de um imóvel, onde passa a organizar a sua vida. Não participou do processo de formação da disposição de vontade, não contribuiu para qualquer eventual vício a ser declarado pelo julgador. Sua posse, conforme apresentaremos, se deu sem conhecimento de quaisquer um dos vícios que potencialmente a maculariam.

Ocorre que, posterior à imissão na posse, o testamento é questionado por via judicial. A controvérsia se assenta sobre uma possível nulidade na constituição do título. A problemática poderia, em se tratando de testamento, por qualquer motivo, uma vez que se trata de um negócio jurídico solene e repleto de formalidades prescritas pelo código. Assim sendo, a título de exemplo, se o tabelião não ler o testamento para uma das testemunhas, o ato é tido como nulo, ignorando completamente qualquer indício da vontade do de cujus. Assim, até mesmo o requisito de aparente menor importância poderia causar sérios problemas para o direito do legatário em questão, não obstante não ter participado do ato.

A possível consequência, no caso da prolação de uma decisão favorável ao pleito de nulidade seria, como já mencionado, a alteração da classificação da posse de boa para má fé a contar da data da citação. Essa alteração iria de confronto direto com o direito já exercido pelo legatário, que o exercera em razão de não possuir ciência do vício.

As sentenças, a depender da finalidade intentada pela ação manejada, se subdividem em "condenatórias, declaratórias ou constitutivas", retomando a classificação apresentada por DONIZETTI $^{23}$. As condenatórias seriam aquelas que impõem a alguém determinada obrigação;

\footnotetext{
${ }^{21}$ CARVALHO, Luiz Paulo Vieira. Direito das Sucessões. São Paulo: Atlas, 2014.

22 Id. p. 117.

23 DONIZETTI, Elpídio. Classificação e efeitos das sentenças definitivas. Disponível em: http://genjuridico.com.br/2017/07/05/classificacao-e-efeitos-das-sentencas-definitivas/. Acesso em 29 de agosto de 2018.
} 
as declaratórias informam a presença ou ausência de direito, a partir de determinado marco temporal; as constitutivas mudam, de fato, a realidade, constituindo novos direitos. Poderia se afirmar que as constitutivas e as condenatórias detêm uma aparente similitude, não obstante que em uma haja a imposição de determinada prática de conduta (ou cessamento de conduta), enquanto a outra busque assegurar a alguém um direito a ser exercido.

Os efeitos de cada uma dessas classificações, logicamente são diferentes. Nas sentenças constitutivas e condenatórias, uma vez que a presença dos elementos modificadores da realidade jurídica dos envolvidos não estivessem ainda configurados, cabe ao juiz, por meio da decisão, a modificação da realidade. Nesse sentido, em uma lógica intrínseca ao próprio ato exarado, a decisão somente pode gerar efeitos quando todos os elementos configuradores do direito já estejam presentes. Nessa toada, por depender em algum grau da própria manifestação judicial como requisito de existência do direito, as decisões gerariam efeitos a contar da inserção do ato proferido no sistema, sendo assim posteriores a da própria decisão.

A sentença declaratória segue a mesma lógica, porém, com resultado diverso. O pleito da ação declaratória objetiva apenas o reconhecimento da situação pelo magistrado, bem como a aplicação do direito à situação fática, em conformidade com a declaração prolatada. É, então, essa conformação que faz com que a sentença declaratória retroaja até a data da origem da situação que ensejou a declaração. Abstratamente, não parece haver problemas com as classificações apresentadas, não obstante essa compartimentalização não ser tão cerrada como era de se esperar dada a diferenciação clara de seus efeitos jurídicos.

Compreendendo o judiciário como um subsistema do direito, assim estruturado por sua própria lógica e criando seus próprios elementos, o juiz se depara constantemente com a necessidade de prolatar decisões. Considerando que, na maior parte dos casos, o juiz não encontra dificuldades na aferição do direito a ser aplicado, a estrutura organizacional se constrói visando uma maior planificação das decisões possíveis, dados os arranjos sistêmicos já construídos. As decisões, nesse contexto, acabam invariavelmente sofrendo influência de outras decisões previamente postas, buscando uma racionalidade jurídica que percebe também as consequências de decidir. ${ }^{24}$

\footnotetext{
${ }^{24}$ Adotamos a corrente de que as decisões judiciais se produzem por meio da associação de elementos existentes no sistema jurídico. Essa associação não é aleatória, sendo pautada pelas decisões que já criaram tais arranjos. " $E l$
} 
En las situaciones de decisión así estructuralmente impuestas, pueden entonces ser incluídos esquemas de racionalidad. Esto significa entonces, que los elementos por relacionar (decisiones) deben ser a su vez presentados como relaciones, por ejemplo como relación entre medio y fin o incluso como relación (óptima) entre varias relaciones posibles entre medios y fin, pero también posiblemente como relación entre principio (regla) y caso, o como relación entre condición desencadeante y acción desencadeada. Pueden entonces hacerse probables estados del sistema en los cuales solo pueden ser incluídas las decisiones en el modo de una unión oficial, cuando pueden presentarse como racionales (en uno u otro sentido)y cuando pueden externar los problemas, las fuentes de error, o las consecuencias no deseadas. ${ }^{25}$

A imposição estrutural que obriga o magistrado à realização da prestação jurisdicional, capitulada como direito fundamental disposto na Constituição Federal de 1988, art. $5^{\circ}$, inciso XXV, impede a não prolação da decisão por parte do mesmo. Essa premissa informa que toda demanda levada ao poder judiciário resultará em uma análise e, assim, surgirá uma decisão (input/output). A decisão, porém, deve levar em conta a complexidade apreensível para o sistema jurídico, se tratando de uma racionalidade que fundamenta a perspectiva de um construtivismo operativo ${ }^{26}$.

Existem critérios mínimos que devem ser respeitados para que a decisão se aproxime da decisão "óptima", tal como descrita, trazendo concretude à abstração jurídica. A racionalidade presente na decisão judicial constitui fundamento da alteração da realidade: o magistrado problematiza as questões relativas à decisão, analisa a historicidade do sistema jurídico para então, compreendido o contexto que será alterado, decidir ${ }^{27}$.

Existe uma forte pressão por parte da estrutura, dado o incremento da complexidade causada pelo sistema, para que sejam planificadas as decisões consoante marcos objetivos, mais seguros. O Código de Processo Civil (Lei no 13.105 de 16 de março de 2015), que atribui à jurisprudência um peso maior do que anteriormente ofertado, dita a tendência da planificação em âmbito judicial de um judiciário em crise. Abarrotados de processos, a alternativa para a

\footnotetext{
comportamiento propio es referido a programas de decisión o a decisiones especiales de otros, en la medida en que cae bajo la presión de la comunicación y de la articulación. Junto con esto, las conexiones con el comportamiento pasado o futuro de otros son puestas abiertamente o mediante implicaciones bajo la premisa de que también han decidido, o bien decidirán y podrían aclarar su decisión con la pregunta de cómo y por qué." (LUHMANN, Niklas. Organización y decisión. Autopoiesis, acción y entendimiento comunicativo. $1^{\text {a }}$ Ed. Barcelona: Anthropos Editorial. 1997.)

${ }^{25}$ LUHMANN, Niklas. Organización y decisión. Autopoiesis, acción y entendimiento comunicativo. $1^{\text {a }}$ Ed. Barcelona: Anthropos Editorial. 1997. p. 23.

${ }^{26}$ Para mais sobre o tema, consultar: LUHMANN, Niklas. O Direito da Sociedade. São Paulo: Martins Fontes, 2016

${ }^{27} \mathrm{Id}$.
} 
economia de tempo e para a melhora das respostas do sistema caminha no sentido de uniformização e burocratização do processo decisório.

Importante ressaltar, nesse sentido, que esse processo de construção de novas decisões parte de algumas premissas. Ao afirmar que "El proceso de constitución no provoca, por lo tanto, que todas las decisiones Sean decididas, sino que cada decisión pueda partir de la base que todas las decisiones son decididas" 28 , o autor descreve o funcionamento sistêmico no qual os elementos são valorados como continentes ou não em um determinado sistema, em razão de sua compatibilidade com a lógica autopoiética intrínseca. É dizer que a lógica de organização daquilo que compõe o sistema jurídico é dada pelo direito, considerando não que todas as decisões são produzidas, mas que todas podem sê-lo, encontrando limitação no próprio sistema. Este, seria assim, um emaranhado de decisões estruturadas que possibilitam novas conexões entre os elementos ali dispostos.

Assim, "Siempre que se impone decidir algo, la decisión conveniente podrá, bajo tales condiciones de constitución, descargarse (y así posibilitarse) mediante la toma en consideración de otras decisiones y, al mismo tiempo, ponerse bajo la presión de ser ella misma una decisión" 29 . Esse contato entre decisões do mesmo sistema aumentariam o que o autor classifica como "mecanismos de amplificación", que diferenciam ainda mais o sistema do seu entorno, aumentando a complexidade do sistema como um todo.

A ampliação da complexidade seria proporcionada pelas decisões contidas no sistema, não retira da decisão sua peculiaridade, vez que encontra amparo nos fatos que geram os efeitos jurídicos. Não obstante ser um processo ancorado na teia, “cada decisión única está más bien constituida dentro de un horizonte de otras decisiones que, a partir de allí, puede ser tratada como algo dado sectivamente relevante" ${ }^{\prime 3}$. Esta planificação, enquanto processo gerador de decisões, é oriunda da incerteza provocada pelas decisões exaradas pelo mesmo sistema, e caminha no sentido de conformar os agentes a um comportamento pré-determinado.

Partir do processo de reconhecimento do testamento, enquanto último ato de disposição patrimonial, que pode ser realizado tanto por vias judiciais ou cartoriais, ambas convalidadas

\footnotetext{
${ }^{28}$ LUHMANN, Niklas. Organización y decisión. Autopoiesis, acción y entendimiento comunicativo. $1^{\mathrm{a}}$ Ed. Barcelona: Anthropos Editorial. 1997. p. 44.

29 id. p. 44.

${ }^{30}$ Id. p. 43.
} 
pelo ordenamento, parece ser o caminho apropriado para compreender as dissonâncias sistêmicas que surgirão. O artigo 610 do CPC/15 dá, não só ao magistrado, mas ao tabelião (caso as partes forem capazes e concordes), o poder de processamento de inventário e partilha. Não serão aqui diferenciados os procedimentos, partindo da mesma premissa: ambos são decorrência da autorização normativa do código, encontrando amparo no sistema analisado dentro do escopo das possíveis decisões. O artigo 612 atribui competência ao judiciário para decidir sobre todas as questões de direito, desde que fatos estejam provados documentalmente. Essas disposições inauguram os efeitos processuais possíveis para declarações de última vontade e, como tais, a inserem no sistema jurídico.

Aberto o procedimento de inventário, existente testamento, ao juiz é dado zelar pelo interesse das disposições ali contidas. Após o devido processamento, o processo é arquivado e os efeitos dos atos praticados se solidificam no mundo. Entretanto, as abstrações jurídicas, por vezes, encontram obstáculos no mundo fático, vícios que podem ser ocasionados por atuações ou simplesmente por omissões. A primeira, a título de exemplo, se daria em casos vícios de consentimento, com a obtenção de uma declaração de forma violenta ou dissimulada, com a atuação direta do agente; a segunda, se daria nos casos de vício de forma, no qual houve erro das partes ou dos cartórios, ensejando nulidades sem que os atingidos tomassem parte em sua constituição.

A problematização levantada pelo presente trabalho diz respeito, porém, a vícios que não tenham contado com conluio ou anuência das partes envolvidas, tendo sido praticados atos juridicamente válidos, ao menos até determinado momento, lastreados em uma decisão viciada. Quando defronta-se com a nulidade de uma decisão anteriormente exarada, os atos praticados sob a sua ótica deixam de ser considerados jurídicos a partir de qual momento?

O juiz, ao reconhecer o devido processamento do inventário, dá ao testamento os efeitos que lhe são esperados: A transmissão da propriedade. $\mathrm{O}$ fato de ter sido encerrado sem controvérsias é um indício de que a transmissão tenha se dado com a devida higidez, indício inclusive para eventual legatário, que tenha vindo a se tornar proprietário de bens por disposição de vontade de outrem. Mesmo com o desenrolar de um procedimento de reconhecimento convalidado pelos julgadores, tendo sido tomadas as devidas precauções, evidenciou-se vício no procedimento de inventário que não tinha sido anteriormente atestado. Considerando o alto grau de formalidade existente para dar forma às disposições ali definidas, não são raras as 
causas de formação da nulidade. A maior dificuldade de controvérsias sucessórias é que os mortos não podem voltar para reafirmar os dizeres já realizados, tornando as formas de disposição de última vontade ainda mais importantes e complexas.

Atestado o vício, tem-se que fixar um marco temporal para que a nulidade opere seus efeitos. Mesmo porquê, não obstante o vício, houve confiança por parte dos envolvidos nas decisões já postas no sistema, até então em conformidade, traduzidas no reconhecimento de validade de um ato central. Muitas vezes, dada a dificuldade de construir uma resposta que enfrente toda a complexidade, se utiliza de um trecho de julgado anterior para que, pautado nas diretrizes do próprio sistema, simplifique a resposta a ser dada - mesmo quando o caso decidido em nada se relaciona com o problema posto. A função do reducionismo, é esperar "una serie de actividades de desplazamiento que cercan la presión de decisión, es decir, la almacenan en sentido real, temporal y social, en aquellos puntos donde momentáneamente no se puede o no se debe decidir" ${ }^{\prime 31}$

A burocratização dos procedimentos encontra forte amparo quando esbarra com estruturas que ocasionam tamanho grau de incerteza como é o judiciário nacional. Reduzir realidades a ficções é, por vezes, necessário, sendo etapa viabilizadora de outras decisões que serão tomadas posteriormente. Existem dois fatores de importante consideração para que seja feita essa redução, porém: o grau de dificuldade de decidir, e a pressão por conformidade. Fato é que as decisões judiciais precisam de tempo para que sejam devidamente fundamentadas, existindo ao mesmo tempo uma forte pressão para que sejam dadas mais decisões, todas em conformidade com o sistema. Esse aparato burocrático não é imóvel, sendo mais rápidas as decisões exaradas, uma vez que podem ser feitas mediante uma carga decisória menor, absorvida pelas decisões precedentes. Assim,

La decisión no es substituida por la inmovilidad, sino por el movimiento. El proceso de comunicación formalmente organizado se transforma en el conductor de transferencias sociotemporales y es precisamente el movimiento de un procedimiento el que justifica el no movimiento de otro. ${ }^{32}$

Esse stress causado pelo excesso de demandas leva a uma alienação por parte dos agentes envolvidos, uma vez que não deterão de todo o tempo que necessitam, sendo reduzidos a meros aplicadores de dispositivos legais interconectados. A alienação, por si, só se torna um

\footnotetext{
31 id. p. 83.

${ }^{32}$ Id. p. $84-85$.
} 
problema quando as decisões não conseguem alcançar no tempo adequado os impactados. Então, dada a insuficiência do sistema, as abstrações tomam o lugar decisões que seriam verdadeiramente prolatadas, passam a servir de pressuposto para as novas decisões a serem tomadas, agilizando o processo de análise e, consequentemente, minorando o tempo para a elaboração da decisão.

Essas abstrações, não podem ser desvinculadas de bases concretas, não podem, portanto, se distanciar da realidade que as motiva. Assim, "Um cambio de los puntos de atención de la decision puede operar com suposiciones y ficciones, pero naturalmente no podría resultar sin

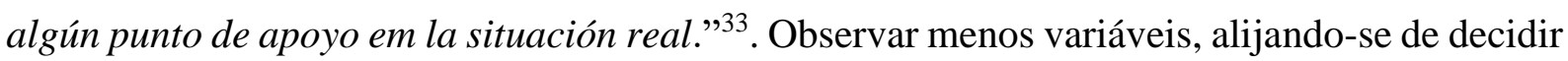
sobre pontos fixos e reorientar o gasto de tempo que impacta de forma direta não só às relações jurídicas travadas como também à credibilidade do judiciário, como estabilizador de condutas, uma vez que todo planejamento é mais complexo que a decisão em si. A criação de ficções facilita o trabalho dos juristas, uma vez que torna-se preciso o pensamento acerca dos conceitos envolvidos e suas correlações. Não é necessário abstrair e tentar compreender todas as variáveis envolvidas, uma vez que o sinuoso não existe sob a ótica do plano. Existe, assim, "la transformación de circularidad en linearidad"34.

O problema dos planos mal feitos é a ausência de coordenação, que pode ocorrer em um âmbito interno (relação entre as decisões da organização), quanto no âmbito externo (relação da organização com o entorno). A planificação não pode ser feita ao alvedrio do que está a se decidir. Nesta toada,

\footnotetext{
La planificación permite, con otras palabras, una suposición reflexiva de suposiciones y esto no en forma arbitraria, sino en forma coordinada y por lo tanto asegurada. La coordinación de las suposiciones conduce, en determinados alcances, al decidir coordinado dando, al mismo tiempo, la securidad para el riesgo de la misma suposición. Pero naturalmente, no garantiza que los resultados se cumplirán en el sentido de las expectativas del plan. ${ }^{35}$ (LUHMANN, 1997. p.77)
}

A boa fé é valor que o sistema buscou proteger. A eleição desse valor é clara em consonância com a análise dos artigos 1.210 a 1.222 do código civil, balizadores para a concessão de direitos, sendo alguns deles o de aferir frutos e de ser ressarcido de benfeitorias realizadas. É importante notar que o caso apresentado dispõe exatamente acerca de eventual

\footnotetext{
${ }^{33}$ Id. p. 85 .

${ }^{34}$ Id. p. 76 .

${ }^{35}$ Id. p. 77.
} 
restituição de frutos, que seria danosa, caso se consubstanciar na prática, fruto de uma abstração oriunda da desconexão dos efeitos jurídicos aos fatos ocorridos.

Contra esse tipo de desconexão, que encontra na planificação um fundamento de existência, é que se funda a proposta deste trabalho. Somente ao compreender que os fenômenos jurídicos não podem simplesmente se descolar do plano da realidade é que pode ser dada à decisão o seu devido poder: o de (re)interpretar a realidade por meio do direito. A decisão é, como já apresentado, produto de diversas outras que lhe antecederam. É inclusive produto das leis, que são formas organizacionais de vincular o indivíduo enquanto integrante da estrutura que cria a si mesma. O sistema jurídico é, por conta disso, um sistema autopoiético, que cria seus próprios elementos e, como consequência, deles não pode se dissociar.

A esse legatário, que teve sua posse convalidada em todos os obstáculos jurídicos apresentados, deve-se ao menos o tratamento de dignidade. Até que seja questionado, este pode exercer livremente do seu direito sobre os bens que integram seu acervo patrimonial, sendo seu incremento fruto de uma decisão exarada pelo sistema. Quando questionado, será este questionamento razão suficiente para levar à alteração dos seus efeitos práticos? Melhor dizendo, poderia a citação em um processo judicial, ao tornar litigiosa a coisa, dar aos envolvidos a ciência da existência de vícios?

A planificação, quando ocorre sem dimensionar os impactos que pode causar pela fixação dos pontos de atenção, acaba aumentando a rigidez da própria estrutura de alienação, limitando a conduta dos agentes das instituições a funções de meros reprodutores de preceitos já postos. Nesse caso, a planificação sobrevém com a classificação dos efeitos possíveis para as decisões judiciais, de maneira que, ao declarar a existência da nulidade, tenta extirpar todos os efeitos já produzidos, ignorando as especificidades da realidade para adequá-la ao plano posto.

Retomando a classificação das sentenças, estas se subdividem, de acordo com a doutrina, em três ${ }^{36}$ possíveis classificações, com efeitos diversos sobre a realidade. As decisões

\footnotetext{
${ }^{36}$ Existem controvérsias acerca das possíveis classificações, conforme aventado por Pontes de Miranda, em sentido de haverem em adição às já postas (condenatórias, declaratórias e constitutivas) as mandamentais e executivas. Com relação à crítica, elucida Didier: "Com a edição da Lei n. 11.232/2005, essa discussão perdeu um pouco a sua razão de ser. Por conta dela, o CPC-1973 foi alterado de forma que toda decisão que reconhecia a existência de dever de prestar (fazer, não-fazer, dar coisa ou pagar quantia) passou a poder ser efetivada no mesmo processo em que fora proferida, não havendo mais necessidade de instauração de um novo processo autônomo de execução.
} 
podem ter efeitos condenatórios, quando estas reconhecem a existência de um direito e viabilizam a satisfação a sua material. Assevera Fredie Didier" ${ }^{37}$ que "a atividade jurisdicional não se exaure com a certificação do direito subjetivo; ela somente se exaure com a efetivação desse direito"38. A constitutiva, por sua vez, "é a decisão que certifica e efetiva direito potestativo"39.

O direito potestativo realiza-se quando completamente imerso nas abstrações jurídicas, razão pela qual a própria decisão se autoexecuta, sem a necessidade de um provimento material posterior a sua prolação. As declaratórias, nesse turno, são descritas por DIDIER como "meramente declaratórias" 40 , restringem-se às hipóteses consoantes no artigo 19 do CPC, dispondo acerca da existência ou inexistência de relação jurídica, bem como de autenticidade ou falsidade de documento. Aqui, ainda se admitem ações meramente declaratórias ainda que tenha ocorrido a violação do direito (art. 20).

O que se vê, pois, é que a decisão meramente declaratória é um minus em relação às decisões constitutivas e às que impõem uma prestação. É exatamente por isso que se acrescenta ao adjetivo "declaratória" o advérbio "meramente": uma decisão pode certificar e determinar a efetivação (decisão que impõe uma prestação), pode certificar e alterar uma situação jurídica (decisão constitutiva) ou pode simplesmente certificar (decisão meramente declaratória) ${ }^{41}$

A declaração tem efeitos irretratáveis para a teoria adotada. A partir do momento em que a declaração é feita, o mundo jurídico não pode mais ignorar sua presença. A decisão judicial é o meio pelo qual a abstração jurídica sai de seu plano utópico e irradia para o concreto. Os efeitos dessa decisão, muito embora tidas como meras declarações, irradiam sem encontrar freios no tempo, atingindo situações já consolidadas. Assim, o autor afirma que "Esse tipo de decisão se caracteriza por ter eficácia retroativa (ex tunc), mas é possível ao legislador, ao menos teoricamente, em situações que entender pertinentes, restringir essa eficácia" ${ }^{22}$.

Perdeu o sentido, pois, distinguir as sentenças condenatórias das mandamentais e das executivas." (DIDIER, Fredie; BRAGA, Paulo Sarna; OLIVEIRA, Alexandria de Oliveira. Curso de Direito Processual Civil. 10. Ed. V. 2. Salvador: Jus Podium. 2015. p.419)

${ }^{37} \mathrm{Id}$.

${ }^{38}$ Id. p. 421.

${ }^{39}$ Id. p. 423.

${ }^{40}$ Id. p. 426.

${ }^{41}$ Id. p. 427.

${ }^{42}$ Id. p. 427. 
Note que o poder de decidir eventuais limites das declarações exaradas não foi posto ao cargo da autoridade que exarou a declaração. Essa limitação aventada por parte da doutrina remonta à estrutura de burocratização existente que gera alienação na estrutura do judiciário. Quando o magistrado reconhece uma situação jurídica, a declara e a torna clara, os efeitos dessa luz irradiam de forma retroativa, vencendo inclusive o tempo já transcorrido no plano da realidade. Essa irradiação não é sem qualquer barreiras, porém.

Consideradas sob a ótica dos marcos temporais objetivos, fixa-se um momento em de transição: a realidade se comporta de uma forma até determinado momento, demarcada ponto de alteração dos pressupostos das relações, colidindo de forma direta com os anteriores. O resultado dessa fixação é, senão, a alteração de todos os atos praticados posteriormente. $\mathrm{O}$ problema é que a ficção jurídica pode não consegue, sozinha, corresponder à realidade subjacente. Muito embora o processualista não tenha descortinado os efeitos práticos dessa "modulação" causada pela classificação da decisão a ser obtida no curso do processo, GONÇALVES ${ }^{43}$ evidencia que

\begin{abstract}
A jurisprudência tem proclamado que a citação para a ação é uma dessas circunstâncias que demonstram a transformação da posse de boa fé em posse de má fé, pois, em razão dela, recebendo a cópia da inicial, o possuidor toma ciência dos vícios de sua posse. Os efeitos da citação retroagirão ao momento da citação, a partir do qual o possuidor será tratado como possuidor de má-fé, com todas as consequências especificadas nos arts. 1.216 a 1.220 do Código Civil. ${ }^{44}$
\end{abstract}

Observa-se que a ausência de limites claros tornaria a decisão, conforme a “jurisprudência” proclama, de difícil inserção na malha jurídica. Isso porque alterar os efeitos que no tempo se produziram, por vezes acortinado por vícios que não dizem respeito diretamente à condição de possuidor, mas do justo título que outrora detinha, gera efeitos que extrapolam a mera declaração. A ciência de ser ou não possuidor de boa ou má fé encontram respaldo na classificação acerca de tais atos pela doutrina do direito civil. A concordância reiterada de que a ciência jurídica de que a citação constitui esse marco para a alteração da classificação oculta o elemento central da discussão, qual seja o conhecimento do vício propriamente dito.

Assim, conforme a sua posição na demanda, se a de a autor ou se a de réu, poderá tomar conhecimento dos vícios da sua posse ou pela citação, ou pela contestação

\footnotetext{
${ }^{43}$ GONÇALVES, Carlos Roberto. Direito Civil Brasileiro: Direito das Coisas. 10. Ed. V. 5. São Paulo: Saraiva. 2015.

${ }^{44}$ Id. p. 100.
} 
apresentada pela parte contrária, malgrado existência de algumas vozes discordantes dessa solução"45

Essa necessidade de criar marcos objetivos para solucionar problemas complexos elaborados pelos sistemas sociais remonta à necessidade de planificação decisória colocada por LUHMANN $^{46}$. O potencial de disrupção que uma decisão pautada em uma planificação mal feita, todavia, já foi objeto de alarde anteriormente. Uma fixação de marco objetivo, que simplifica a tarefa do julgador e o faz depositar seu esforço em outros horizontes, acaba suprimindo a necessidade de efetiva comprovação da tomada de consciência por parte deste possuidor, uma vez que deve-se considerar a possibilidade de que o legatário pode nunca ter tomado consciência de sua irregularidade. A criação de balizas objetivas deveria ter como objetivo atingir esse possuidor cuja ciência do vício poderia nunca se dar. Criar a ficção jurídica para, lastreado em um vício efetivo, tornar previsível todos os efeitos só é possível em razão da adoção de uma presunção e, com isso, delimita-se as decisões que serão exaradas posteriormente. Assim, a planificação, neste caso, padece do vício da simplicidade.

Quando o processo deixa de ser o meio de discussão e se torna o cerne da questão, as decisões, que poderiam - e deveriam - ser usadas em benefício social público, acabam se transformando em engrenagens que circulam apenas em nível de abstrações jurídicas. Entender que esse possuidor, malgrado considerações de GONÇALVES ${ }^{47}$, não tem, necessariamente, a ciência do vício que macula sua posse e sua propriedade através da simples citação ou contestação. É imprescindível essa compreensão para a demonstração de que manipulações da realidade sem amparo fático oferecem mais riscos que soluções, descortinando outras amarras que não estão evidentes para qualquer observador.

\subsection{O poder da jurisprudência fantasma}

Para entender os motivos que levam GONÇALVES ${ }^{48}$ a ter tanta confiança no passado institucional, é necessário inquirir que jurisprudência é essa que proclama com tamanha serenidade que a citação válida seria o marco de transição, para que se possa entender em que

\footnotetext{
${ }^{45}$ Id. p. 100.

${ }^{46}$ LUHMANN, Niklas. O Direito da Sociedade. São Paulo: Martins Fontes, 2016

${ }^{47}$ GONÇALVES, Carlos Roberto. Direito Civil Brasileiro: Direito das Coisas. 10. Ed. V. 5. São Paulo: Saraiva. 2015.

${ }^{48}$ Id.
} 
medida impactam a estrutura das decisões aqui analisadas. Até porque, vale ressaltar, a classificação da posse impacta diretamente nos direitos que advêm dela. Considerar a ciência subjetiva sem que efetivamente ela se comprove, deixando a cargo de uma manifestação processual, tão simplória como um "cite-se", a alteração dessa condição de manifestação de consciência, é aceitar a assunção de riscos decorrentes da presunção de má-fé objetiva. O risco agrava quando o autor assevera que "essa regra não pode ser considerada absoluta", reiterando na sequência que: "Apesar da crítica dos doutrinadores, a jurisprudência, como já se viu, entende deva-se presumir a má-fé do possuidor desde a data da citação ou, conforme a hipótese, desde a data do conhecimento dos termos da contestação. "(g.n. $)^{49}$

Dentro do âmbito dos fatos, é impossível regredir à situação passada, na qual só a abstração jurídica pura pode atingir, uma vez que os efeitos da decisão anterior já foram manifestados - partindo da possibilidade de declaração judicial no processo de inventário. Os bens foram transferidos, possuídos como se não houvesse qualquer mácula e, dado o reconhecimento da nulidade, a situação futura será, por certo, alterada. Esse interstício lacunoso, porém, compreendido entre a decisão e a citação, como fica? Será que a jurisprudência deu cabo a essa questão e solucionou, de forma brilhante e, de algum modo, oculta, razão pela qual a doutrina que a cita entendeu por não explicitar?

Até então, com as explicações oferecidas pelo autor, constatam-se duas citações de julgados, quais sejam RTJ 99/804 ${ }^{50}$ e RJTJRS 68/393 ${ }^{51}$. Não obstante não terem sido elencados os paradigmas a qual se referiu, tendo se limitado a referir as revistas de jurisprudência e as páginas correspondentes, tentaremos delimitá-los, em alguma medida, para possibilitar maior clareza argumentativa em vista do problema enfrentado. Essa fixação arbitrária mascara todos os dados que a compõem, dando ar de objetividade frente ao que não é tão objetivo assim. É digno de nota que com essa referência não se sabe qual a natureza dos julgados delineados, a sua importância para a definição jurisprudencial que leva a uma presunção de má fé, nem mesmo o ano em que foram exaradas.

GONÇALVES escrevera o volume citado em 2015, ano de prolação do Código de Processo Civil vigente, que modificara em algum grau a importância e as formas que essa

\footnotetext{
${ }^{49}$ Id. 101.

${ }^{50}$ STF. Revista trimestral de jurisprudência. V. 99. Brasília: Supremo Tribunal Federal. 1982. p. 804 - 807.

${ }^{51}$ TJRG. Revista de Jurisprudência do TJRGS. N. 68. Rio Grande do Sul: Tribunal de Justiça do Rio Grande do Sul. 1977. p. $390-394$.
} 
jurisprudência influiria no direito posto. Não é qualquer julgado, entretanto, que pode ser considerado jurisprudência, devendo essa sempre se pautar na racionalidade argumentativa e na sua similitude ao caso que se pretende solucionar.

Malgrado as considerações feitas, a jurisprudência consolidada erige sob duas publicações, uma, a RTJ 99, de 1980, outra, RJTJRS 68, 1977. A primeira crítica que deveria surgir, neste contexto, é relativa a qual sistema jurídico foi base para a jurisprudência. Neste interstício, marcado de 1977 a 2015, a jurisprudência citada pelo autor sobreviveu a uma nova constituição $^{52}$, um novo código civil, um novo código de processo civil, dentre outros ordenamentos ordinários pós-constituídos. As alterações são tantas que se o autor tivesse tão somente assinalado o ano dos julgados, já seria motivo suficiente para verem suscitados questionamentos de dirersas ordens.

Iniciando a análise pelo RTJ 99/804, chegar-se-á ao julgado do Recurso Extraordinário de $n^{\circ} 92.862$ - PR, prolatado ainda sob a égide do antigo código civil, datado de 26 de agosto de 1980, com a seguinte ementa:

Ação reivindicatória. A posse injusta a que se refere o art. 524 do Código Civil, é a que se insurge contra o exercício do direito de propriedade, estabelecendo uma luta entre ela, ainda que ad interdicta, e o domínio. Recurso extraordinário conhecido e provido, para julgar procedente a presente ação reivindicatória. ${ }^{53}$

Em uma análise atenta, o relatório informa que a sentença de primeiro grau entendeu pela falta de um requisito essencial para a propositura da ação, qual seja a posse injusta dos requeridos. Nesse ínterim, foi interposto recurso de apelação que foi parcialmente provido (apenas surtiu efeito contra um dos apelados). Por fim, foi interposto o Recurso Extraordinário com fulcro em divergência jurisprudencial acerca da negativa de vigência dos artigos 524 a 530, bem como artigos 300 e 302 do Código de Processo Civil. Do relatório uma ponderação interessante cabe ser frisada, tendo o Ministro ponderado acerca da prova produzida pelos

\footnotetext{
${ }^{52}$ Essa, especificamente, não pode ser tida como uma ruptura institucional completa, não afastando a priori a possibilidade de um julgado atingir os fatos posteriores. Não obstante, a crítica da descontextualização se faz necessária para problematizar o poder dado aos doutrinadores, especialmente no emprego de argumentos de autoridade consubstanciados por "jurisprudência", tornando qualquer argumento posterior rejeitado de plano pelo sistema, como faz o próprio autor quando contraria o absoluto da decisão, mas diante dela acalenta-se e a aceita como resposta.

${ }^{53}$ STF. Revista trimestral de jurisprudência. V. 99. Brasília: Supremo Tribunal Federal. 1982. p. 804 - 807. p. 804.
} 
recorridos que, embora consolidada nos autos, não poderia se sobrepor ao título de domínio dos autores.

A discussão teve como ponto central a redação do artigo 524 do Código Civil de $1916^{54}$, discutindo a respeito da abrangência do termo "injustamente", se a aplicação seria restrita ao possuidor injusto ou se abarcaria, outrossim, a qualificação não justa da posse. Concluíram os julgadores pela abrangência do termo que, quando usado em sentido genérico, não qualifica somente a posse injusta, mas sim todas as outras que não se qualificam como justas, citando Pontes de Miranda, nos seguintes termos:

“É claro que o Código, no art. 524, toma a expressão em sentido genérico e nem de outro modo poderia ser, sob pena de destruir ele próprio o princípio em que define as qualidades que compõem a noção complexa de domínio"55

Assim, julgaram procedente a demanda para considerar a posse dos recorridos a contar da citação como injusta, modulando a decisão nos moldes do julgado RJTJRS 68/393, citado pelo Ministro relator.

Consolidado que o precedente original é o publicado na Revista de Jurisprudência do Tribunal de Justiça do Estado do Rio Grande do Sul - o segundo citado -, passemos à análise do paradigma gerado pelo julgado do Recurso Extraordinário nos Autos da Apelação Cível 28.727, que teve como ementa a seguinte:

Ação reivindicatória. A promessa de compra e venda não levada ao registro público somente confere direito pessoal ao promissário comprador e não pode ser oposta a terceiro em ação reivindicatória. Recurso extraordinário inadmitido por incorrer violação de norma de direito federal a aceitação de tal tese. ${ }^{56}$

Conforme exposto no relatório, o recorrido adquiriu um imóvel por meio de escritura pública lavrada em 19 de novembro de 1975. Este imóvel se encontrava na posse da recorrente, que a detinha em razão de cessão dos direitos de contrato de compra e venda mediante recibo de arras, não tendo sido este instrumento levado a registro público.

\footnotetext{
${ }^{54} \mathrm{O}$ art. 524 do Código Civil de 1916 dispunha que: "A lei assegura ao proprietário o direito de usar, gozar e dispor de seus bens, e de reave-los do poder de quem quer que injustamente os possua."

55 TJRG. Revista de Jurisprudência do TJRGS. N. 68. Rio Grande do Sul: Tribunal de Justiça do Rio Grande do Sul. 1977. p. $390-394$.

${ }^{56} \mathrm{Id}$.
} 
Neste ponto, combate o julgador a ideia de oponibilidade a terceiros que não pode ter um instrumento não registrado, segundo excerto infra:

\begin{abstract}
"Tenho para mim, Sr. Presidente, que o digno magistrado de primeiro grau bem analisou a matéria. Se contrato de promessa de compra e venda existe, este não fora registrado e, portanto, não podia ser oponível a terceiros. Se o promitente vendedor, titular do domínio, resolver transferir o imóvel a outrem, é problema dele, e o relacionamento anterior não afeta a nova situação. Se lesão sofreu o promitente comprador de contrato não inscrito no Registro Imobiliário, ela deverá ser verificada em ação direta contra o mencionado promitente vendedor. A posse dos apelantes, a partir da citação, tornou-se injusta e, portanto, cabível a condenação em perdas $e$ danos como deixou assente o digno Juiz de primeiro grau. ${ }^{\prime 57}$ (p.393)
\end{abstract}

Nota que se trata de discussão acerca da justiça da posse. Assim, cabe explicar a diferença entre a posse justa e a posse de boa-fé, para que, traçadas as distinções cabíveis, sejam elucidadas as cristalinas considerações da jurisprudência que, posterior ao desnudar dos acórdãos citados, mais sombrias revelaram-se que clarividentes. A posse justa, conforme disposição do código civil, é a que "não for violenta, clandestina ou precária (Art. 1.200), enquanto a de boa-fé se dá quando "o possuidor ignora o vício, ou o obstáculo que impede a aquisição da coisa. (Art. 1.201). QUINTELLA e DONIZETTI ${ }^{58}$, por meio de um exemplo simples, demonstram a sutileza da classificação intentada pelo código.

\begin{abstract}
Suponhamos, por exemplo, que a posse de Orlando é precária, pois este deixou de restituir matéria que lhe foi emprestado. Manuel, sem ter ciência disso, toma a coisa emprestada de Orlando. Nesse caso, a posse de Manuel tem defeito - há injustiça, devida à precariedade. Não obstante, é de boa-fé, porquanto Manuel desconhece do vício. ${ }^{59}$
\end{abstract}

A distinção fica mais clara quando as classificações geram aparentes contradições, na qual Manuel tem a posse viciada em razão de uma apropriação indébita mas ainda assim a desconhece, mantendo o elemento de convicção intacto. Esse "salto" classificatório muda muito a realidade das duas classificações. Enquanto para a primeira, em que há violência, clandestinidade ou precariedade as condições não se cessam, a segunda possui uma condicionante, qual seja a ciência do vício. A perda da qualidade de boa-fé, se dá no "momento em que as circunstâncias façam presumir que o possuidor não ignora que possui indevidamente" (Art. 1.202), sendo o único requisito legal diferenciador de ambas a cognição, ao menos a presumida cognição.

\footnotetext{
${ }^{57}$ Id. p. 393.

${ }^{58}$ QUINTELLA, Felipe; DONIZETTI, Elpídio. Curso didático de direito civil. 3. Ed. São Paulo: Atlas, 2014.

${ }^{59}$ Id. p. 686.
} 
Planificar decisões que versem sobre posse justa e injusta é uma tarefa muito mais simples do que em boa e má fé em decorrência deste único aspecto. Reduzir subjetividades a marcos objetivos é negar a realidade como ela se dá em benefício de um formalismo operativo. Provar elementos subjetivos é processo muito sutil, devendo ser criada uma regra de cognição mínima, sob pena de desconsiderar toda a subjetividade por meio de marcos objetivamente fixados.

Explicitamente, então, o que se vê é o funcionamento da autopoeise em seu locus, o sistema cria seus próprios elementos por meio da codificação dos efeitos produzidos pelos fatos, de tal forma que os fatos constituem, em alguma medida, efeitos jurídicos intrínsecos. A decisão judicial em um provimento declaratório de vício, conforme descrito, aclara a concepção que o sistema jurídico tem daquele elemento específico, mas não diz respeito, ao menos a princípio, aos efeitos causados pelo ato.

O provimento declaratório é, conforme apontado por DIDIER ${ }^{60}$, uma mera declaração, mas que muda todas as concepções de realidade tecidas pelo mundo jurídico. Os atos praticados sob o manto de uma nulidade podem ter se dado de forma a inexistir o conhecimento em todas as etapas. Quando o legatário tem sua posse questionada, ainda não conhece certamente se, de fato, as nulidades ali alegadas existiram, considerando especialmente a ausência de influência, qualquer que seja, para a configuração do vício. A sentença torna claro o vício para todos os efeitos, sendo inegável para o sistema jurídico que aquele ato é eivado em sua essência. A prática de atos pautados em uma certeza precária não tira desses atos a sua essência: o desconhecimento do vício em todas as etapas até a prolação da decisão judicial.

O judiciário não tem para si uma arma de poderes ilimitados uma vez que a decisão é, por si só, fundamentada. $\mathrm{O}$ fundamento para alteração da característica que tira da posse a sua boa-fé é a unívoca ciência do vício, que só pode, no sistema jurídico, ser produzida pelo poder judiciário. O judiciário, enquanto apreciador do direito material, não se atém a meros formalismos - ou não deveria - para fixar marcos restritivos de direitos para partes de boa-fé, mesmo porque esses são, em alguma medida, vítimas da própria sorte. A decisão que ignora

\footnotetext{
${ }^{60}$ DIDIER, Fredie; BRAGA, Paulo Sarna; OLIVEIRA, Alexandria de Oliveira. Curso de Direito Processual Civil. 10. Ed. V. 2. Salvador: Jus Podium. 2015.
} 
tais fatos não só é caduca em seus possíveis fundamentos jurídicos como ineficaz para a finalidade do sistema jurídico.

O direito, enquanto sistema social gera respostas autoritárias, impostas aos indivíduos. A decisão, enquanto conector da abstração normativa ao suporte fático, tem em si o elemento da interdição, alterando as conexões realizadas posteriormente à sua inserção no sistema. Contudo, a função do direito não é aparelhar o maquinário de legitimação de opressão por parte de uma casta de privilegiados. A interdição como força bruta por parte do estado não diferencia este do grupo de bandidos que molda outrem à sua vontade. A luta do constitucionalismo ocidental, como aponta OLIVEIRA ${ }^{61}$, se funda em direitos, garantias e deveres fundamentais, que legitimam até mesmo o uso de opressão por parte do estado.

Os princípios e valores, resguardados e garantidos pelo constitucionalismo ocidental, são os verdadeiros vetores que norteiam a autopoiese jurídica, intrínsecos à própria lógica do sistema. Os vetores, como apontados pelo autor, distoam dos empregados pela doutrina e “jurisprudência” colacionados, uma vez que restringem o campo de aplicação a uma pseudo funcionalidade, removendo requisitos legalmente impostos visando uma redução de complexidade sistêmica. Correspondem, nesse sentido: (i) ao balanceamento da autonomia pública face à privada (utilização de métodos coercitivos para fazer cumprir ordens); $a$ pluralidade social e o mínimo existencial substantivo (traduzida pelo negligenciar explícito por parte das autoridades julgadoras do emaranhado de decisões que vinculam a própria prática jurisdicional); e a solidariedade e a corresponsabilidade na efetivação dos legítimos interesses coletivos internos e internacionais $^{62}$ (consubstanciada na interpretação fática pré valorada, desconsiderando a realidade de todos os atingidos pelas decisões do sistema).

A investigação, no campo organizacional, se dá pela tentativa de entender e racionalizar as decisões, que emaranhadas, moldam sistemas em meio a um aparente caos. Investigar, nesse sentido, é dar luz aos pressupostos que raramente sofrem questionamento. A doutrina, quando veste a roupa do mago, desvia a atenção para onde a mágica realmente acontece. A jurisprudência, enquanto elemento conformador da planificação, como descrito em

\footnotetext{
${ }^{61}$ OLIVEIRA, Márcio Luís de. A Constituição juridicamente adequada: transformações do constitucionalismo e atualização principiológica dos direitos, garantias e deveres fundamentais. Belo Horizonte: Arraes Editores Ltda., 2013.

${ }^{62}$ Id. p. 228.
} 
LUHMANN $^{63}$, eleva os argumentos ali veiculados à altura de autoridade, por força de uma decisão impositiva. A ausência de crítica leva à deturpação do sistema jurídico em alguns de seus aspectos. Produzir elementos sob uma lógica jurídica é não se alijar da responsabilidade de decidir, é não negar a realidade que se construiu com o seu crivo, indo contra a historicidade processualmente apreensível do sistema jurídico. A racionalidade é intrínseca ao direito, uma vez que a fundamentação discursiva é o próprio fundamento de validade democrática da justiça, que se diferencia do executivo e legislativo que são representativos (ou assim deveria ser). Uma decisão que nega a realidade juridicamente constituída em prol de uma ficção processual, qualquer que seja, informando apenas que a norma processual atribui a esse tipo de decisão um determinado tipo de efeito é, nesse sentido, antijurídica e antidemocrática.

As ficções estão presentes em todos os horizontes investigativos do observador. As organizações criam expectativas sobre as concepções de realidade vigentes. Apesar de serem necessárias as ficções, é necessária atualização dessas expectativas frente às anomalias, que são observações na qual a expectativa da teoria não se revela na prática. $\mathrm{KUHN}^{64}$, ao descrever a estrutura das revoluções científicas, informa que a ocorrência dessas anomalias é o primeiro passo para a ruptura dos preceitos "dogmatizados". A forma com a qual lida-se com a anomalia é que determina os rumos da nova ciência que se molda. LUHMANN ${ }^{65}$, em sua última crítica incisiva à burocratização, a qual sintetiza as ideias aqui desenvolvidas, aponta que a racionalidade é a única forma de desmascarar as amarras pré postas, assim,

\begin{abstract}
Una situación tal no es solo objeto de investigación científica, debe reaccionar de acuerdo a su estructura y condiciones de existência, sensiblemente cuando no defensivamente, ante uma investigación, sin poder integrar ella misma parte de la responsabilidad de decisión, intenta incitarla a la racionalization y democratización, y a más innovaciones, pero que, por outra parte, descubre y desenmascara las ficciones, descargas y defensas internas. $" 66$
\end{abstract}

Não é, portanto, por se denominar julgados de jurisprudência, que esses passam a operar efeitos de forma indiscriminada e dissociada dos fatos que lhe dão suporte. É exatamente desse mal uso de expressões que detêm autoridade que arbitrariedades são cometidas e a racionalidade jurídica é posta à prova.

\footnotetext{
${ }^{63}$ LUHMANN, Niklas. Organización y decisión. Autopoiesis, acción y entendimiento comunicativo. $1^{\mathrm{a}}$ Ed. Barcelona: Anthropos Editorial. 1997.

${ }^{64}$ KUHN, Thomas S. A estrutura das revoluções científicas. São Paulo: Perspectiva S.A, 1998.

${ }^{65}$ LUHMANN, Niklas. Organización y decisión. Autopoiesis, acción y entendimiento comunicativo. $1^{\mathrm{a}}$ Ed. Barcelona: Anthropos Editorial. 1997.

66 Id. p. 98.
} 


\section{CONSIDERAÇÕES FINAIS}

O presente trabalho tentou condensar um debate filosófico com a materialidade do direito, atuando, em alguma medida, como voz intermediadora entre os anseios planificadores dos processualistas e da pureza de elementos volitivos imaculáveis. Descrever a realidade do legatário que, não só tem sua posse tomada em um ato violento do estado, mas também tem sua voz silenciada dada a insignificância de sua realidade. Entender o direito como conformador de expectativas aliados a vetores humanizadores é entender que a resposta simples, por vezes, cria mais problemas que as complexas, simplesmente por faltar a essa a consideração das variáveis impactadas - o que não falta àquelas.

A solução pautada na ignorância das particularidades do exercício da posse bem como fundada em uma leitura pouco atenta dos julgados referenciados cria uma espécie de câncer na ordem jurídica vigente. Por meio de um erro interpretativo as decisões replicam uma ideia incorreta sobre a modulação dos efeitos da posse do legatário e, conforme mencionado, alteram a sua rotulação jurídica, carregando consigo efeitos patrimoniais relevantes.

Assim, os frutos obtidos, as benfeitorias realizadas deverão ser apuradas pela realidade que se mostrou, não pela ficção jurídica ditada a posteriori. Uma decisão que declara um vício em um instrumento de testamento não deveria ignorar a realidade do terceiro de boa-fé que foi, até a prolação da decisão, proprietário e possuidor. A ficção jurídica não deveria planificar a complexidade da realidade sem enfrentar as peculiaridades do caso concreto.

O reducionismo deliberado do sistema, quando conflita com sua própria lógica de existência, deve ser podado antes que sua contaminação irradie e produza efeitos em outras esferas de análise. Abandonado o misticismo que envolve uma jurisprudência desprovida de base, a delimitação justificada de um marco temporal pela perspectiva material se mostra mais eficaz do que a imposta por classificações exclusivamente realizadas sob critérios processuais. Objetivando terminar em filosofia, a pergunta que fica é: Se não a razão por meio da argumentação, existem limites para frieza da ficção jurídica? 


\section{REFERÊNCIAS BIBLIOGRÁFICAS}

BEVILAQUA, Clóvis. Codigo Civil dos Estados Unidos do Brasil. 6. Ed. V. 6. Rio de Janeiro: Livraria Francisco Alves, 1932.

BEVILAQUA, Clóvis. Direito das Coisas. V. 2. Brasília: Senado Federal, conselho editorial, 2003.

CARVALHO, Luiz Paulo Vieira. Direito das Sucessões. São Paulo: Atlas, 2014.

CATEB, Salomão de Araújo. Direito das Sucessões. 5. Ed. São Paulo: Atlas, 2008.

DIDIER, Fredie; BRAGA, Paulo Sarna; OLIVEIRA, Alexandria de Oliveira. Curso de Direito Processual Civil. 10. Ed. V. 2. Salvador: Jus Podium. 2015.

DINIZ, Maria Helena. Curso de Direito Civil Brasileiro. 28. Ed. V. 5. São Paulo: Saraiva, 2013.

DONIZETTI, Elpídio. Classificação e efeitos das sentenças definitivas. Disponível em: http://genjuridico.com.br/2017/07/05/classificacao-e-efeitos-das-sentencas-definitivas/.

Acesso em 29 de agosto de 2018.

GOMES, Orlando. Direitos Reais. 2. Ed. Tomo 1. São Paulo: Forense, 1962.

GOMES, Orlando. Sucessões. 13. Ed. Rio de Janeiro: Forense, 2006.

GONÇALVES, Carlos Roberto. Direito Civil Brasileiro: Direito das Coisas. 10. Ed. V. 5. São Paulo: Saraiva. 2015.

KUHN, Thomas S. A estrutura das revoluções científicas. São Paulo: Perspectiva S.A, 1998.

LUHMANN, Niklas. O Direito da Sociedade. São Paulo: Martins Fontes, 2016

LUHMANN, Niklas. Organización y decisión. Autopoiesis, acción y enentendimiento comunicativo. $1^{\text {a }}$ Ed. Barcelona: Anthropos Editorial. 1997.

LUHMANN, Niklas. Sociedad y sistema: la ambición de la teoria. Ed. Barcelona: Ediciones Paidós Ibérica, 1984.

OLIVEIRA, Arthur Vasco Itabaiana de. Elementos de Direito das Sucessões. 2. Ed. Rio de Janeiro: Jornal do Commercio Rodrigues, 1929.

OLIVEIRA, Arthur Vasco Itabaiana de. Tratado de Direito das Sucessões. 4. Ed. V. 1. São Paulo: Max Limonad, 1952.

OLIVEIRA, Márcio Luís de. A Constituição juridicamente adequada: transformações do constitucionalismo e atualização principiológica dos direitos, garantias e deveres fundamentais. Belo Horizonte: Arraes Editores Ltda., 2013. 
PEREIRA, Lafayette Rodrigues. Direito das Coisas. Brasília: Senado Federal, 2004.

QUINTELLA, Felipe; DONIZETTI, Elpídio. Curso didático de direito civil. 3. Ed. São Paulo: Atlas, 2014.

TJRG. Revista de Jurisprudência do TJRGS. N. 68. Rio Grande do Sul: Tribunal de Justiça do Rio Grande do Sul. 1977. p. 390 - 394.

STF. Revista trimestral de jurisprudência. V. 99. Brasília: Supremo Tribunal Federal. 1982. p. $804-807$.

RIBAS, Antonio Joaquim. Acções Possessorias segundo o direito pátrio comparado com o direito romano e canônico. Rio de Janeiro: H. Laemmert \& C, 1883.

RODRIGUES, Silvio. Direito Civil. 27. Ed. V. 5. p. 31. São Paulo: Saraiva, 2002.

ROSElVALD, Nelson; FARIAS, Cristiano Chaves de. Curso de Direito Civil. 12. Ed. V. 5. Salvador: Jus Podium. 2016.

ROSElVALD, Nelson; FARIAS, Cristiano Chaves de. Curso de Direito Civil. 11. Ed. V. 1. Salvador: Jus Podium. 2013

SCHWARTS, Germano. Introdução à teoria do sistema autopoiético do Direito. Ed. Porto Alegre: Livraria do advogado, 2005.

Data de Submissão: 28/10/2020

Data de Aceite: 24/03/2021 